\title{
Payment for research participation: a coercive offer?
}

\author{
A Wertheimer, F G Miller
}

Department of Bioethics, National Institutes of Health Bethesda, Maryland, USA

Correspondence to: Franklin G Miller, Department of Bioethics, Clinical Center, National Institutes of Health, Building 10, Room 1C118, Bethesda, Maryland 20892-1156, USA: fmiller@nih.gov

Received 12 June 2007 Accepted 2 August 2007

\begin{abstract}
Payment for research participation has raised ethical concerns, especially with respect to its potential for coercion. We argue that characterising payment for research participation as coercive is misguided, because offers of benefit cannot constitute coercion. In this article we analyse the concept of coercion, refute mistaken conceptions of coercion and explain why the offer of payment for research participation is never coercive but in some cases may produce undue inducement.
\end{abstract}

Informed consent is a basic ethical requirement for most research involving competent adult subjects. ${ }^{1}$ All the leading codes of research ethics and the US federal regulations stipulate that consent should be obtained in a manner that is free of coercion or undue influence. ${ }^{2-4} \mathrm{~A}$ major area of concern about coercion and undue influence in the literature of research ethics has been payment of research subjects as an inducement to participate. Ruth Macklin noted in a 1989 article that "the reason for holding that it is ethically inappropriate to pay patients to be research subjects is that it is likely to be coercive, violating the ethical requirement that participation in research should be fully voluntary." Recently, the charge of coercion surfaced in ethical commentary on a phase I trial of a novel monoclonal antibody agent TGN1412 that caused drastic inflammatory responses in several healthy subjects who had been offered $£ 2000$ (approximately US\$3500) for participation. ${ }^{6}$ The consent document stated that "If you leave the study and exercise your right not to give a reason or are required to leave the study for noncompliance, no payment need be made to you." Greg Koski, former director of the US Office of Human Research Protections, remarked, "That's very coercive language."

Bioethicists have worried about the practice of paying subjects to participate in research for several reasons. Some worry that the practice may compromise the scientific integrity of research, because it will motivate prospective subjects to withhold important information. Some worry that it will wrongly commodify a practice that should be based on altruism. Some worry that it may lead to injustice if some groups are more likely to respond to financial incentives than others. Here we focus primarily on the widespread claim that financial payment can be coercive and can therefore compromise voluntary informed consent.

At first glance, it is a patent conceptual and ethical confusion to regard the offer of financial payment for research participation as coercive, since it is an offer and not a threat. Indeed, the Belmont Report appears to deny that such offers could be coercive: "Coercion occurs when an overt threat of harm is intentionally presented by one person to another to obtain compliance." Although we believe that this first glance is correct, the persistence of ethical concern over the coercive potential of payment in clinical research suggests the need for a careful examination of two issues: (1) can the offer of financial payments be coercive? (2) if the answer to (1) is no, why do so many mistakenly believe otherwise?

Can the offer of payment to research subjects be coercive, thus undermining informed consent? Ruth Macklin has said that the question of how large a payment constitutes a coercive offer is one for "which no clear answer is forthcoming". We disagree. A clear answer is forthcoming, namely, that genuine offers do not coerce. The key issue here is not merely semantic-the appropriate use of the word coercion-but the ethical implications of describing conduct as coercive. In view of the ethical significance of informed consent and the widespread use of payment as an incentive for research participation, the status of coercive offers has considerable practical import in the ethics and regulation of research with human subjects.

The claim that the offer of financial payments can actually constitute a coercive offer in a manner that undermines informed consent is both false and incoherent, because genuine offers cannot coerce. In some circumstances the offer of financial payments may compromise the validity of consent if the subject is unable to respond in a rational manner, thus unduly inducing research participation; however, such offers do not invalidate consent by means of coercion.

It is often claimed that financial payments can be coercive if they motivate people to do something that they would otherwise not do. This is a mistake. If $A$ persuades $B$ to give blood by giving $B$ reasons as to why she should do so, then $A$ gets $B$ to do something that B would otherwise not do, but A hardly coerces B to do so or renders B's consent involuntary or invalid. If $\mathrm{A}$ induces $\mathrm{B}$ to mow his lawn by offering $B$ a financial payment, he may get $\mathrm{B}$ to do something $\mathrm{B}$ would otherwise not do, but it doesn't follow that B's consent is invalid or involuntary. Moreover, and contrary to what many seem to think, the size of the offer is irrelevant to coercion. A larger offer may be more efficacious in motivating the subject to accept one's proposal, but it is no more coercive. Sweetening the pot does not make it sour.

A word about our method. In considering the coherence of the claim that financial payments for research are coercive, we deliberately appeal to examples in other domains of human affairs. Our aim is to counteract the parochialism of research ethics, which tends to make ethical assessment of 
consent for research participation in isolation from other contexts in which consent is solicited. We return at the end of the article to the theme of parochialism as an important factor explaining the erroneous assessment of financial payment for research participation.

\section{ANALYSIS OF COERCION}

To assess the alleged coerciveness of financial payment, we need to examine the conceptual question, What is coercion? Although we shall not argue for this proposition here, there is no univocal account of coercion that applies across all contexts in which that concept is invoked. For present purposes, we will be focusing exclusively on what constitutes the illegitimate coercion that invalidates consent, as distinct from the legitimate coercion associated with sanctions for violating the law. We contend that what we call the rights-violating view of coercion offers the best account of that concept for those contexts in which coercion invalidates consent. ${ }^{9}$ On the rights-violating view, A coerces $B$ to do $\mathrm{X}$ in a way that invalidates $\mathrm{B}$ 's consent only if (1) A proposes or threatens to violate B's rights or not fulfil an obligation to B if B chooses not do X and (2) B has no reasonable alternative but to accept A's proposal. Both conditions are necessary. For present purposes, the main point is that A's proposal is coercive only if A's "declared unilateral plan" - what A proposes to do if B does not do X-would violate B's rights. When the (paradigmatic) gunman says, "Your money or your life", the victims are coerced to hand over their money because the gunman's declared unilateral plan (to kill them) if they do not comply violates their rights and because they have no reasonable alternative but to acquiesce.

It can be argued that a simpler account of coercion is that $A$ coerces B when A threatens to make B worse off than B's status quo baseline. There is often little difference between the worseoff and the rights-violating accounts. However, when the two differ, the rights-violating approach is more accurate, because it allows us to handle (1) cases in which $A$ has a right to make $B$ worse off than B's status quo, and also (2) cases in which A has an obligation to render B better off than B's status quo.

To illustrate (1), a prosecutor does not coerce defendants into pleading guilty to a crime in exchange for a relatively lenient sentence when he proposes to take them to trial if they do not plead guilty, even though both options-pleading guilty and going to trial-are worse than B's status quo. Why? Because the prosecutor's declared unilateral plan to take the defendants to trial does not violate their rights and relative to that option, the prosecutor is actually making an offer of leniency rather than a threat of severity. And offers do not coerce. The defendants' guilty pleas are voluntary.

To illustrate (2), if a physician (A) has an obligation to provide a patient $(B)$ with medical services free of charge, say, because $\mathrm{A}$ is employed by the national health service, then $\mathrm{A}$ actually does coerce B into paying a fee if A proposes not to provide such services unless B pays. And this is so even though A does not propose to make $B$ worse off than at present if $B$ declines. Why? Because the physician's declared unilateral plan-not to provide B with services free of charge-would violate B's right to free medical service from the national health service. The physician's "offer" to provide service in exchange for a fee is more accurately understood as a threat not to provide services unless a fee is paid. And threats are coercive. Similarly, if A threatens not to treat $B$ or to withhold treatment from $B$ unless $B$ enrols in a research study, that might constitute coercion, since $B$ may have a right to receive treatment from $A$. By contrast, A's offer of financial payment if B enrols in the study is not coercive, since $B$ has no right to receive payment from $B$ if $B$ does not enrol in the study.

Although coercion is often presented as a psychological phenomenon, it is important to note that A's coercive threat does not necessarily nor even typically compromise the rationality of B's decision or overwhelm B's will. In the standard case of coercion, A threatens to violate B's rights if B does not acquiesce, and $\mathrm{B}$ makes a perfectly rational decision that in the circumstances it is in his or her interest to acquiesce. Coercion is a function of the normative structure of the choice situation in which A has placed B. Coercion is not a function of the psychic stress on B and does not require an "overborne will".

Consider a case of extortion. A is a mobster. B owns a restaurant. A says to $B$, "You may find that the windows on your restaurant are broken unless you agree to hire my company to remove your garbage. Think it over. Talk to your friends. Talk to the police. Let me know if you want to hire my company next week." B might make a perfectly rational decision to hire A's company. B may calmly weigh the costs and benefits of compliance and come to the judgement that it is better to comply after learning that the mobster has the police in his pocket as well. A has definitely coerced B to hire his company because his declared unilateral plan (to break the windows of B's restaurant) would violate B's rights, and this is so even if A frames his proposal as an offer not to break the windows if $B$ hires his company.

On the rights-violating view of coercion, A coerces B to do X, and thus compromises the voluntariness or validity of B's consent, only if A proposes or threatens to violate B's rights if $\mathrm{B}$ does not do X. By contrast, A does not coerce B to do X if A proposes to give a benefit to $B$ (to which $B$ is not otherwise entitled) if B does X. Simply put, whereas threats are coercive, genuine offers are not. Whereas threats reduce the options available to the target, offers expand the options, and one does not coerce another when one's proposal expands rather than contracts the agent's options.

Some scholars, nevertheless, defend the view that genuine freedom-enhancing offers can also be coercive. Perhaps the most thoughtful analysis is Joel Feinberg's discussion of his now famous case of "the lecherous millionaire", which might serve as a model for examining whether financial payment for research can be conceived as a coercive offer. ${ }^{10} \mathrm{~B}$, who is poor and lacks health insurance, needs money to pay for expensive surgery that can save her child's life. A, a millionaire, indicates that he will pay for the surgery if $\mathrm{B}$ becomes his mistress for a period. Feinberg argues that A's offer is coercive because his proposal rearranges B's options such that B has "no choice" but to accept. Interestingly, although Feinberg thinks that it is reasonable to say that an offer can be both coercive and freedom-enhancing, he also maintains that the "purely conceptual question" is "inherently murky", and that it is "not theoretically important". Feinberg thinks that the important question is "what bearing ... the coerciveness of an otherwise freedom-enhancing offer has on the consent which it produces". And here, Feinberg says that the B's consent is not invalidated by A's offer. As he notes, A could "hardly be convicted of rape". Since Feinberg holds that a freedom-enhancing offer does not invalidate consent, and since we are interested in coercion in the research context precisely because of its effect on the validity of consent, to refer to such offers as coercive is highly misleading.

\section{MISTAKEN CONCEPTIONS OF COERCION}

The claim that offers of financial payment can be coercive is based on what we will call the "no-reasonable-alternative view" 
of coercion. ${ }^{10}{ }^{11}$ This is a natural but deeply mistaken view about coercion. It is a natural view because it is true that one generally has no reasonable alternative but to succumb to a coercive proposal, as in the gunman case. Moreover, as we indicated above, having "no reasonable alternative" is, itself, a necessary condition of coercion. But it does not follow that one is coerced just in case or because one has no reasonable alternative but to accept A's proposal. Having no reasonable alternative is simply not a sufficient condition of coercion. And it is important to see why.

There are two ways in which we might interpret "having no reasonable alternative", and neither amounts to coercion. On one view, one has no reasonable alternative when the distance between the alternatives is so great that it would be irrational to reject the better alternative, and (virtually) no one would do so. If A offers B $\$ 1000$ to mow his lawn (a one-hour job), B may have no reasonable alternative but to accept, given the distance between the two options: (1) \$1000 for mowing A's lawn, and (2) no money for not mowing A's lawn. Yet B obviously is not coerced. Commentators sometimes support the view that one can be coerced by a very attractive offer by invoking the wellknown phrase from The Godfather: "My father made him an offer he couldn't refuse." But Michael Corleone's reference to an "offer" here is clearly ironic. Don Corleone's proposal was a paradigmatically coercive threat- "Either your signature or your brains will be on the contract."

A second interpretation of "no reasonable alternative" focuses on the unacceptability of B's situation if B rejects A's proposal. On this view, A's offer is coercive if rejecting it would leave $B$ in dire straits. Although this view has the ring of plausibility, it simply cannot be correct. The error in this view is perhaps most obvious in cases of medical care for lifethreatening conditions. For example, suppose that a biopsy has shown that $B$ has a malignant tumor. Her breast oncologist tells $B$ that she is unlikely to survive more than a year unless she has surgery. B is referred to A, a surgeon, and consents to A's offer to perform the surgery.

Note that there is certainly a sense in which B has "no reasonable alternative" to accepting A's offer. Moreover, refusing A's proposal will leave $B$ in an unacceptable position. Still, A has not coerced B and, more importantly, we would never say that A has performed surgery on B's breast without B's informed consent just because $B$ had no reasonable alternative. Indeed, patients often have no acceptable alternative to consenting to an offered medical procedure. The implications for research are important. In some cases when investigators offer financial payment to prospective participants if they consent to enrol in a protocol, the participants may have no reasonable alternative but to do so. However, analogous to the example of breast surgery, those payments would still not thereby constitute coercion.

It is sometimes claimed that an offer of financial payment can be coercive when A knowingly takes advantage of B's vulnerability. ${ }^{11}$ But this, too, can't be right. B would not agree to hire a roofer if her roof was not leaking, but B's vulnerability does not preclude her consenting to have the roofer repair the leak. The need for assistance does not preclude voluntary consent. So, too, with the need for money. For example, B is selling her house because she is taking a job in a different city. She listed the house for $\$ 300000$ but has lowered the price to $\$ 200000$ because the move is pending and she is desperate to sell. A agrees to pay $\$ 200000$. Although B is in a vulnerable position, $B$ can hardly claim that her agreement to sell has been coerced. If $\mathrm{B}$ signs the contract and unexpectedly receives a better offer, we do not think that $\mathrm{B}$ can renege on her contract and then claim that she had signed under duress because she was desperate. Her prior consent is perfectly valid. The issue in dispute is not just conceptual. To regard B's decision as coerced would have unfortunate practical consequences for both $\mathrm{A}$ and $B$. It would be unfair to A to void the agreement between $A$ and $B$ when A has no responsibility for creating B's situation. More important, it would be unfair to B. For if B's consent were regarded as coerced or invalid, then $A$ would probably avoid transacting with $B$. And $B$ may very much want A to transact with $B$ under these conditions.

Interestingly, those who argue that the offer of financial payments to prospective participants can be coercive often proceed as if there were something especially coercive about financial offers as opposed to the offer of medical treatment or the possibility of medical treatment that would otherwise be unavailable. This makes no sense. There may be reason to think it is more ethical to offer medical treatment (as contrasted with money) in exchange for participation in a research study, but there is absolutely no reason to think it is less coercive. Indeed, if coercion is a function of the degree of psychological "pressure" on the subject (which we deny), the prospect of going without medical treatment may be more coercive than the prospect of forgoing a financial payment.

Although the offer of financial payments for participation in research does not invalidate consent because of coercion, such offers can result in invalid consent if the prospective subject is not able to make a competent and rational decision in response to the offer. An agent's response to an offer may be compromised by decisional myopia, that is, the tendency to overweight the short-term benefits and underestimate or underweight the long-term costs of accepting the proposal. Thus, B's current needs and desires may so overwhelm her decision-making that A's proposal elicits a decision that does not serve B's long-term interests and that she would not make were she to weigh the costs and benefits rationally. Just as drug addicts display what George Ainslie calls "hyperbolic discounting" of the future costs of their behaviour relative to the immediate gratification (or avoidance of discomfort), prospective participants may excessively discount the future costs of their participation. ${ }^{12}$ So B may wrongly believe that it is in her interest to accept A's offer, when it is not.

This is the territory of undue inducements. It is important to appreciate that the distinction between an unproblematic (nonundue) inducement and an undue inducement is not a feature of the inducement itself. It is a function of the relation between the inducement and the subject's response to it. As a general category, an inducement is undue only when it predictably triggers irrational decision-making given the agent's own settled (and reasonable) values and aims. As the official IRB guidebook puts it, an offer is troublesome if it is so "attractive [that it] may blind prospective subjects to the risks or impair their ability to exercise proper judgment" about the risks of participation. ${ }^{13}$ Distortion of judgement is the key. An inducement is not morally problematic simply because it motivates the target to make a decision he or she would otherwise not make, if it is reasonable or in the recipient's interest to accept the proposal. An offer is not problematic if it is genuinely too good to refuse. It is problematic if it seems to be too good to be refused and would be refused if the agent's judgement were not blinded or clouded or impaired.

\section{DIAGNOSIS OF ETHICAL ERROR}

If we are right to claim that offers cannot be coercive, why have so many persisted in making this conceptual and ethical error? We speculate that, apart from the conceptual mistakes that we have 
analysed above, two factors help explain the persistence of inappropriate use of the language of coercion with respect to clinical research.

First, the historical legacy of abusive experimentation in which investigators have exploited human subjects continues to colour the ethical appraisal of clinical research. In the wider culture this is reflected in the label of "guinea pig" to describe human subjects. Accordingly, human research evokes moral discomfort, as research participants are being used to advance science and promote the social good. Incentives for research participation heighten the moral discomfort. Moreover, like coercion, financial payments get people to do something they might otherwise not do and referring to such offers as coercive is, perhaps, the strongest condemnatory language we have available.

Second, ethical commentary on clinical research is parochial. Ethical assessments of the research enterprise typically are not tested by examining comparable situations in other domains of human affairs. We submit that the situation of financial payment for research is no different-with respect to coercion-from payment for public service jobs, such as sanitation, police, firefighting, and military service, all of which carry risks to workers for the benefit of society. Indeed, arguably we should be less concerned about threats to the voluntariness of research participation, owing to the regulatory system in which research studies are prospectively vetted by research ethics committees and written informed consent is required. ${ }^{14}$ Seeing participation in these public service activities as voluntary and free of coercion should give us pause in viewing payment for research participation as coercive. In short, the tendency to regard financial payment for research participation as coercive reflects an excessively narrow ethical vision. There may or may not be reasons to worry more about financial payment to research participants than to firefighters, but those reasons have nothing to do with the coerciveness of financial payments.

\section{CONCLUSION}

As we noted above, the practice of offering financial payment to research participants has raised a variety of concerns, most of which we do not address here. But if we are to assess those concerns in a proper manner, it is important to be clear as to which concerns have merit and which do not. If we are right, we should simply abandon the concern with coercion in the case of payment for research participation. The offer of financial payment does not coerce because it cannot coerce. Ethical concerns about undue inducement remain insofar as payment has the tendency to promote irrational decision-making. The question as to when the offer of financial payment actually constitutes an undue inducement is a topic that merits separate analysis.

Competing interests: The authors have no competing interests to declare.

The opinions expressed are those of the authors and do not necessarily reflect the position or policy of the National Institutes of Health, the Public Health Service or the Department of Health and Human Services.

\section{REFERENCES}

1. Emanuel EJ, Wendler D, Grady C. What makes clinical research ethical? JAMA 2000;283:2701-11

2. Annas GJ, Grodin MA. The Nazi doctors and the Nuremberg code. New York: Oxford University Press, 1992.

3. World Medical Association. Declaration of Helsinki. JAMA 2000;284:3043-5

4. United States Department of Health and Human Services. Protection of Human Subjects. Code of Federal Regulations. 45CFR46. Washington, DC: USDHHS, 1991.

5. Macklin R. The paradoxical case of payment as benefit to research subjects. IRB 1989;11:1-3.

6. Emanuel EJ, Miller FG. Money and distorted ethical judgment about research: ethical assessment of the TeGenero TGN1412 trial. Am J Bioeth 2007:7:76-81.

7. Bloomberg. Parexel misled subjects sickened in London study, ethicists say. 10 April 2006. http://www.iconocast.com/News Files/BNews6 18B 06/Biz3.htm laccessed 13 Mar 2008).

8. National Commission for the Protection of Human Subjects of Biomedical and Behavioral Research. The Belmont Report. Washington, DC: US Government Printing Office, 1979.

9. Wertheimer A. Coercion. Princeton: Princeton University Press, 1987.

10. Feinberg J. Harm to self. New York: Oxford University Press, 1986:229-42

11. McGregor J. "Undue inducement" as coercive offers. Am J Bioeth 2005:5(5):24-5

12. Ainslie G. Breakdown of will. New York: Cambridge University Press, 2001.

13. Office for Human Research Protections. Institutional Review Board guidebook. United States Department of Health and Human Services, http://www.hhs.gov/ohrp/ irb/irb guidebook.htm (accessed 27 Feb 2008).

14. Miller FG, Wertheimer A. Facing up to paternalism in research ethics. Hastings Cent Rep 2007:37:24-34 